\title{
31. South-East European perspectives
}

\section{Norbert Buzás and Miklós Lukovics}

\section{INTRODUCTION}

Science and innovation are an integral part of the structure of nearly all modern societies (Owen et al. 2013) and are becoming increasingly important in the South-East European countries. In general, uncertainty, ignorance and negative side-effects connected to innovation have created a school of thought that feels science, research and innovation should be responsibility driven with reference to its impacts on society, human beings, the environment and its externalities (Owen et al. 2012; von Schomberg 2013; Fisher and Maricle 2014). Science and innovation can be shaped in responsible ways (Guston 2008).

Although the topic of responsible research and innovation (RRI) has gained credibility in the world's scientific thinking and in the European Union's (EU's) policy over recent years, RRI is a relatively new concept for the transition economies including many countries in the South-East Europe area.

This chapter is mostly based on the results of the Facilitating Responsible Innovation in South-East European Countries (FaRInn) project, ${ }^{1}$ and on supplementary primary research carried out by the authors. In an exciting but complex environment, this project had the overall objective of enhancing the framework conditions and paving the way for an innovation model in South-East Europe that respects the principles of RRI: sustainability, social responsibility and better quality of life. Eight partners from seven Southern European countries cooperated over a two-year period to achieve this objective. Here, starting from an overview of the geographical context, we summarize the most important achievements of the project, demonstrating the challenges facing the countries with a changing innovation environment. This covers the results of surveys carried out on the innovation pipeline and examples of pilot actions undertaken to test RRI models. Based on these results, we formulate a proposal for a process of RRI implementation in this region that takes into consideration its specific socio-economic conditions.

\section{CHANGING CONTEXT OF THE INNOVATION ENVIRONMENT IN SOUTH-EASTERN EUROPE}

In order to understand the special features of the South-East European (SEE) area in connection with responsible research and innovation, we should first get a better insight into the general economic status and the unique characteristics of the innovation environment in this group of countries.

Given that this chapter focuses on the experiences of the FaRInn project, we have to define South-East Europe based on the related operational program. The program area is located at the south-eastern edge of the EU. While the program is a part of the internal cohesion policy ${ }^{2}$ of the EU, it actively seeks the full participation of non-member states, 
so the program area includes 16 predominantly small countries, with a total population of 200 million and a geographical area of 1.9 million square kilometers. It is one of the most diverse and complex transnational cooperation areas in Europe.

This is the only transnational program area in the EU with such a large number of non-EU countries participating (for example, candidates with an application for EU membership under examination, potential candidates which are EU partners in the association process but not yet recognized as a candidate, and third countries) (EC 2013a). In terms of gross domestic product (GDP) per capita of SEE countries, there is a clear distinction between old and new EU member and non-member states. All regions below 50 percent of the average EU GDP level are located in the new EU member, candidate, potential candidate or third countries. The GDP per capita is less than 50 percent of the EU average in more than half of the territory of the SEE area, so this area can be characterized as lagging behind (Eurostat 2015).

Looking specifically at innovation capacity, the majority of the program area is missing or lacking innovation strategies. A 2012 report demonstrating the regional differentiation of innovative activities in the EU (EC 2012), proposes a range of indicators to measure the innovation potential of regions. It shows that Eastern and Southern Europe are overwhelmingly behind on the key indicators.

In the old member states, innovation facilities (such as science parks and technology transfer institutions) are essential partners for implementing innovation strategies. In the new member states such institutions have been established over the past 10-15 years, but regional diffusion is much lower. In most of the less favored areas these facilities and institutions are mostly missing, as are adequate strategic concepts. It should be underlined, that gross domestic expenditure on research and development (GERD) is generally low in comparison to EU average. Only a very small part of the SEE area has GERD figures higher than the EU average, and in most of the candidate and potential candidate countries very low expenditure in research and development (R\&D) is noted (Eurostat 2015).

The performance of SEE countries in terms of business sector expenditure on R\&D (BERD) is low. The share of business enterprise $R \& D$ expenditure on total R\&D expenditure ranges between 24 and 60 percent in the SEE countries, whereas EU average shows a share of 64 percent by the business sector (EC 2013b). Similarly, indicators for regional distribution of business R\&D intensity show that intensity is only high in the capitals of Southern, Eastern and South-Eastern Europe. In the remaining parts, the level of R\&D intensity in the business sector remains rather low (EC 2012).

Universities and science centers are concentrated in major urban areas and/or the regional economic centers. Thus, the situation concerning higher education expenditure on R\&D (HERD) per capita shows a clear dichotomy between most Western, Central and Northern European Member States, on the one hand, and most Southern and Eastern European states on the other. Shares of HERD are high in many of the northern and central member states (except Germany), whereas their share in the Southern and Eastern member states is low, with only the capital cities constituting notable exceptions (EC 2012).

Over the past 20 years, the number of researchers and scientists in SEE countries has seriously decreased, as highly educated people leave their countries in search of a better life. The EU's working-age population peaked in 2011, with Southern and Eastern 
European countries more affected by the shrinking labor force than northern and western countries (EC 2014a). Experts leave their country for better professional fulfillment abroad (external brain drain), or they leave their professions for better paid jobs in the private sector (internal brain drain) (UNESCO 2009; Stankovic et al. 2013).

Some progress can be observed concerning the adoption of the educational and research system in the less favored countries. Eâstern and Southern European countries have been experimenting with a structural change underlined by the ongoing upgrading of their economic structures and knowledge intensity of their economies over the past decade (EC 2014a). However, some of the small countries of this group did not fulfill the requirements set out in the Bologna Process ${ }^{3}$ and the implementation of the existing legislation is still weak (UNESCO 2009). In its Europe 2020 Strategy, the EU set the target of reaching a tertiary attainment rate among young adults (aged 30-34 years) of 40 percent by 2020 . The latest figure (in 2012) is 35.8 percent. Twelve EU member states have already reached or surpassed the 40 percent EU target, but there are strong differences in the level reached and in the rate of progress between member states. Nordic and Western European countries tend to have high rates of tertiary attainment. Southern, Central and Eastern European countries tend to show lower rates (EC 2014a).

As we have recently concluded, ${ }^{4}$ the latest European innovation union scoreboard ${ }^{5}$ (EC 2014b) helps us to summarize the situation presented above (see Figure 31.1). Grouping the EU member states into four different performance groups, it shows that one member state represented in the SEE cooperation area (Slovenia) is an innovation follower (second group - with innovation performance above or close to that of the EU average), while six (Croatia, Czech Republic, Greece, Hungary, Italy and Slovakia) are moderate innovators
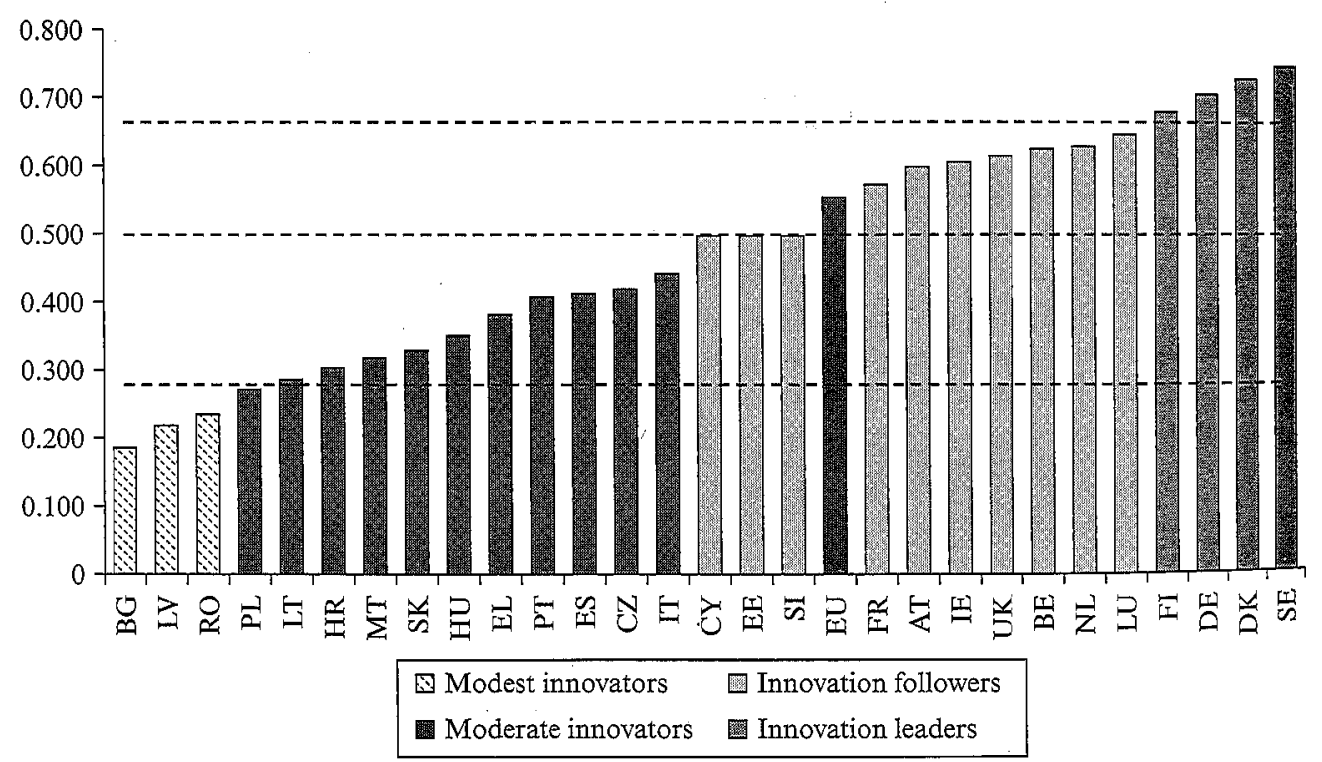

Source: European Commission (2014b).

Figure 31.1 Summary of European Innovation Union Scoreboard 2014 
(third group - performance below that of the EU average), while two (Bulgaria and Romania) are modest innovators (final group - performance well below that of the EU average). None are allocated within the first group, innovation leaders (where innovation performance is well above that of the EU average).

Research by UNESCO (2009) stated that since 2000 there has been progress in all the SEE countries in reforming the most important institutions responsible for innovation processes, including the ministries, universities, research institutes and academies of sciences. Substantial reforms of existing institutions have been introduced, but the role of informal and indirect relationship between stakeholders, the high level of corruption and political influences on innovation activities still exist in these countries. A number of new institutions have also been set up in order to diversify available education systems, promoting research and development and the diffusion of innovation. Though these reforms have not always been quick and complete, as discrepancies frequently arise between the adoption of new legislation and its implementation, progress achieved so far across the SEE countries can be considered adequate, and there are a number of exemplary cases with significant achievements.

The research also shows that SEE countries still face specific problems which influence the decision-making process and action planning, for example, the lack of inter-sectoral cooperation between ministries responsible for higher education, research and innovation, the traditional organization of universities or the lack of a university development strategy. The SEE countries have seen meager success in the area of innovation, characterized by low participation of the business sector in R\&D. Policies to better integrate the $R \& D$ sector with industry are being developed, but one of the preconditions is to improve the growth capacity of the industry which, in turn, will increase its need for R\&D and innovation.

According to our empirical observations made during the FaRInn project, it should be emphasized that the role of governmental financial support (grants and tenders, including EU financial sources) in stimulating innovation activities is much higher than in the developed countries. In SEE countries the market demand for a new product or service is less frequently cited as the motivation behind companies' innovation activity. As shown above, BERD is extremely low in South-East Europe and companies tend to avoid the risk connected with financing uncertain innovation activities, and do not finance it (EC 2014b). This highlights the role of governmental grants: a large number of companies apply for EU co-financed financial resources to carry out innovation activities. However, while the output of such grants may comply with the expected indicators of the grant, it does not necessarily respond to market demand. This paradox should be taken into account when analyzing innovation activities in SEE countries.

\section{SPECIAL GEOGRAPHICAL FEATURES OF RRI}

As responsible innovation (RI) is still an emerging concept, with no widely accepted indicators for territorial-level evaluation, partners of the above-mentioned FaRInn project decided to overcome this difficulty by undertaking primary research on the most relevant questions of RRI among the players of the innovation system. The members of the innovation system were classified in two groups: 
1. Actors, who directly contribute to the production of innovation (for example, innovative enterprises and research facilities).

2. Stakeholders, who are not directly connected to the innovation activity, but indirectly have huge influence on the actors and the whole innovation system (policy makers, chambers, professional associations and so on).

The methodology to collect input from the actors was a questionnaire. A common questionnaire frame was developed and used by each partner. The 23-item questionnaire was designed based on the following main topics:

1. General information about the organization (6 questions).

2. Innovative activity (4 questions).

3. Responsible innovation (13 questions).

The selection of the actors questioned was based on pre-existing partner relationships. The questioned parties were contacted by email with a request to complete the online questionnaire. In some cases, actors were also contacted by telephone to increase the response rate. Nearly 210 actors participated in the survey. In each case, microenterprises dominated the sample of respondents. The background of the respondents covered a wide range of sectors from tourism to high-technology scientific research.

The stakeholders were questioned in the form of in-depth interviews. The partners analyzed the most relevant stakeholders and classified them in different groups including, but not limited to, development/innovation agencies, local councils, chambers of commerce, research centers, professional associations, financial institutions, local councils and other public authorities, clusters and civil society organizations. Each partner defined the most relevant groups of stakeholders in their area and delivered the stakeholder interview with one member of each group. Thus, inputs were collected reflecting diverse approaches. The stakeholder interview framework was common for each partner; the focus areas covered the general concept of RI, its responsibility dimensions, its level of awareness and the connection with actors. Altogether, 80 in-depth interviews were delivered. The majority of the responders reflected the ideas of public sector, innovation agencies and chambers.

The results of the local analysis show that some actors and stakeholders are aware of certain elements and responsibility dimensions of RRI, but they hardly know the comprehensive concept itself. They also believe that the definition and characteristics of the negative environmental, ethical and social effects cannot be clearly defined. Thus, a common understanding is missing. Among the responsibility dimensions, the environmental dimension is the most known and used, while the ethical dimension receives the least attention.

The research showed that only a few people know the concept of RI and many people have never heard of it. The unknown nature of the concept causes some negative attitude among actors and stakeholders towards RRI. If we analyze the current practical approach towards the responsibility dimensions among the players of the innovation system, it is clear that long-term effects on innovation are not considered and little attention is paid to the avoidance of different negative and unwanted side-effects of innovation activity (social, ethical or environmental).

It was also found that information on RRI is missing. The actors do not have internal motivation to design their operation in line with RRI principles (except in some special 
industries, for example, biotechnology where the specific legal requirements imply some RRI aspects) and the stakeholders (rather than the companies themselves) are the bodies in which aspects of RRI first appear, if they appear at all.

Since the communication system among the bodies of the innovation system is complex and works with low effectiveness, it also contributes to the problem. The stakeholders, in most cases, lack the necessary influence on the activity of actors, because in new member states and especially in non-member states of the SEE region small and medium-sized enterprises (SMEs) lock themselves out, and are not willing to cooperate with stakeholders. The lack of cooperation in general, and not just in communication, is a serious problem in this group of countries.

The vast majority of the stakeholders and actors agreed that RRI principles need to create some financial benefit for the institutions, as based on their current financial situation they cannot cope with further expenses in order to make their operation more responsible. However, if the necessary financial resources were available, the actors of the innovation space would be ready to experiment with the co-design and co-implementation of RRI. Even this finding further supports the lack of awareness about RRI. Actors and stakeholders are not aware of or convinced by the potential economic potential of RRI. They seem to see it as an additional burden, rather than a strategy that could promote their overall competitiveness.

A common characteristic of the partner areas (mostly Greece, Montenegro, Romania and Slovenia) is that they would require further infrastructural development (roads, ports, facilities, and so on) to be able to 'step up'. The most relevant common weakness of the partners relates to the structure of the business sectors. The dominant elements are the SMEs in all of the examined partner areas. The missing mid-sized companies with development potential rarely exist and the few big companies do not generally aim to enhance local development. One important disadvantage is that SMEs focus on local and regional markets, which are too small, and thus the lack of resources (lack of qualified workforce and capacity) and development is an everyday problem. The efforts for economic survival distract attention from the development of a long-term, strategic innovation culture. For these SMEs becoming and remaining competitive is an extremely difficult challenge. To aggravate the problem, high-quality services for business development are also missing, and entrepreneurs are culturally encoded not to request help to develop their business.

The low level of trust and lack of willingness to cooperate can be observed in almost every partner area (Slovenia being the exception). These countries can be characterized as suffering from extreme trust deficit economics. The entrepreneurs protect their knowledge carefully and do not intend to participate in any cooperation initiative that can distract their attention from the core business activity, without offering any financial compensation for their efforts. The situation is aggravated by a lack of complex programs and program packages to support cooperation among sectors and the involvement of different levels of governance. The nonexistence of these complex packages deprives the territories of the effective allocation of resources. The lack of cooperation between sectors and different levels sets back the comprehensive design of new development models and makes the communication and dissemination of new tendencies, such as RRI, slower and more resource intensive.

The few initiatives existing in the partner areas still focus on the research aspects rather than on the implementation of RI in the corporate sector. The same is experienced in 
the policy environments. The policy makers do not see RI as an unexploited potential to development, but consider RI as a new burden to avoid. Thus, they do not plan to improve the RI level of the territories by providing financial support for the implementation of principles. In the long term this is a serious drawback,' as the attitude change towards RI needs to be initiated and supported by the policy environment and development agendas envisioned by the policy makers. Allocating financial support for this development is necessary as it can serve as external motivation for the actors and stakeholders (who currently do not have inner motivation in this regard) in creating, implementing and testing RI models.

\section{SUPPLEMENTARY FINDINGS ON THE UNIQUE CHARACTERISTICS OF INNOVATION AND RRI IN THE SEE COUNTRIES}

The results we gained during the FaRInn project raised scientific and practical questions to which we expected answers from the experts of innovation living in the SEE countries. To specify the special characteristics explored by the FaRInn project, we created a survey that we sent to some of the experts of innovation in the SEE countries. The survey questions in connection with the SEE countries' innovation and RI were generated in a way that their answers could be compared with the answers received from people in the comparator group of countries. Therefore, we adapted the majority of our questions from the RRI Science and Technology Survey ${ }^{6}$ and from the Delphi Exercise Questionnaire. ${ }^{7}$

We evaluated the attitude of countries in connection with innovation and RI on the basis of answers to 24 questions that 29 experts asked in Italy, Serbia, Hungary, Romania, Bosnia and Herzegovina, Slovenia, Belarus, Montenegro and Slovakia. The survey is statistically not representative, but informative from the point of view that all the respondents are well known and acknowledged practical experts of innovation in their countries. In this section we present those results, which demonstrate the specialties of the SEE countries most decisively.

For half of the responder experts innovation means Schumpeter's five types of innovation (Schumpeter 1912 [2004]); while for approximately 40 percent of them innovation means any process that brings something new to a system. All this means a broader interpretation of innovation than in developed countries, where it puts more focus on the practical approach of innovation: technological innovation. In connection with this, according to 70.8 percent of respondents, the proportion of technological innovation of all the innovation activity in their countries is less than 30 percent. This percentage significantly lags behind the proportion in developed countries. Furthermore, the territorial concentration of the technical innovation is strong in the SEE countries, since 70.8 percent of the respondents are of the opinion that innovation mainly affects the capital and main, larger cities. Contrary to this, technological innovation in developed countries is far more decentralized.

According to the experts questioned, the main motivation for the innovation activity in the SEE countries is first the accessibility of public money. The significant difference compared with developed countries is that market demand is an insignificant encouragement factor. In the respondents' countries, technological innovation is mainly funded by 
research and development and innovation $(\mathrm{R}+\mathrm{D}+\mathrm{I})$ grants $(66.7$ percent). Furthermore, enterprises receive government-financed grants (62.5 percent). On the basis of the answers to another question, 66.7 percent of the respondents marked EU-funds as the most important fund accessible for financing the innovation activities. Meanwhile, 16.7 percent of them marked governmental funds and the private funds as the most important sources for innovation. Consequently, the dominance of the EU-funds and grant-driven innovation as a phenomenon is clearly visible in the SEE countries.

To the question of in which phase of the value chain they would handle potential social and ethical risks, respondents from the SEE countries and from the comparator survey's countries were concentrated at almost the same rate in the early planning phase and the whole value-chain stream.

To the question of who they would involve in the identification and evaluation of RI's possible social and ethical aspects, most of the respondents emphasized the role of research institutes and educational institutions (50 percent). Moreover, they highlighted their role in duties to strategy-makers (45.8 percent), research-funding organizations (45.8 percent) and trade associations ( 45.8 percent). The comparator survey's responders settled on the following order of priorities: strategy-makers ( 76 percent), ethical committees ( 64 percent), non-governmental organizations (NGOs) ( 56 percent), decision-makers (50 percent), research institutes ( 78 percent) and end-users ( 44 percent).

As far as the methodological aspect is concerned, the respondents would principally include the concerned parties with the help of focus-group interviews on the identification and evaluation of the possible social risks and ethical viewpoints of the RI. Also, regardless of the country the answer came from, the respondents consider developing a network, including researchers, moneylenders, strategy-makers, individuals and other commissions deemed suitable for the task.

The respondents, independently of country groups, find the lack of clear rules as the main obstacle to integration of the RRI concept into the industrial sphere. They also find the scarce awareness of the RRI concept in the concerned territories as another obstacle.

Drawing youth into science is a very important strategic issue, however, to the question of whether the (national) government is doing too much, enough or too little to stimulate young people's interest in science, the vast majority of SEE respondents ( 83 percent) chose the option that their government does too little. The dissatisfaction of the EU27 countries' respondents is also conspicuous ( 65 percent).

The majority of the respondents ( 74 percent) believe that scientists in governmental laboratories and universities strive to act responsibly during their research activity. Only 4.3 percent of them believe that they do not consider the RI aspects. Judgment of the responsible attitude of scientists who work in private laboratories is more divided; 60 percent of respondents believe that their research activity is responsible, while 30 percent think that they do not take the effects of the research activity into account. As regards judgment of environmental activities, most of the respondents declared positively (74 percent). The judgment of consumer protection is split: 52 percent of the responders believe that they try to take account of the effects in connection with their activities linked to the research activities, and 39 percent of them think this is not characteristic.

Compared with the results of the survey, conducted in the EU27 territory, the judgment of scientists working in governmental laboratories, universities, private laboratories and environmental commissions is similar. Nevertheless, the respondents of the survey, 
conducted in the EU27 territory had a more favorable opinion in connection with the judgment of the responsibility of consumer protection's activity. On the basis of these two studies, the evaluation of the governmental representatives and the industrial sphere is also alike. If respondents take the social and ethical effects of the activities related to the research activity of the two groups into consideration, the EU27 and the current study question the behavior of governmental represêntatives even more.

A significant majority of those asked ( 82.6 percent) believe that science and technology make our life easier, more comfortable and healthier. This question was also in the form of to what extent the respondents agree with the statement that science and technology make our life healthier. In this case, the answers show a more skeptical picture; only 43.5 percent of them agree with the statement, while nearly 9 percent of the respondents completely disagree with it. The results of the EU27 survey show the same opinion.

The majority of the responders ( 34.8 percent) totally disagree with the statement that we are too dependent on science, while 21.7 percent of them agree with it. In case of the survey conducted in the EU27, 32 percent of them disagree with it but the number of people who agree is higher ( 39 percent).

Thirty-nine percent of respondents agree that science affects our life too fast, 21.7 percent of them abstained and 34.7 percent of them disagree. Contrary to this, 62 percent of respondents from the EU27 consider this process too fast, revealing a greater concern for the effects of science. However, responders to both surveys agree that owing to science and technology there are more opportunities available for future generations. Nearly 35 percent of respondents believe that the application of science and technology may threaten human rights; while the results of the EU27 survey show a bigger concern (more than half of the responders agree that science and technology threaten human rights). The possibility that science and technology, if fallen into the wrong hands, can be used as a tool of terrorism in the future worries the two surveys' respondents to nearly the same proportion.

\section{SOUTH-EAST EUROPEAN PERSPECTIVES}

In SEE countries we face a large number of special situations, which differ significantly from more developed countries. This may influence our efforts to introduce RRI tools in this group of countries. Their general economic situation and the unique characteristics of the innovation environment (small size, that is, lack of critical mass, a low level of GDP per capita, a very low level of BERD, grant-driven innovation paradox, the role of informal and indirect relationships between stakeholders, a high level of corruption, political influence on innovation activities, high territorial concentration of innovation activities, a lack of highly developed R\&D infrastructure, and technology transfer), must be taken into consideration when thinking about RRI.

Beyond that, the attitude of the innovation actors and stakeholders is also very characteristic in these countries: awareness of RRI is very low, and this limited knowledge of the concept seems to cause negative attitudes. Generally, low levels of trust and lack of cooperation poses a serious problem to this group of countries. Moreover, the struggle for economic survival has distracted attention from the development of a long term, strategic innovation culture. The actors do not have internal motivation to design their operation in line with RRI principles. 
It should be highlighted that the RRI readiness of these countries is much lower than that of more advanced countries, so the introduction of RRI should start by taking small steps from raising awareness, to more comprehensive approaches, taking into account local circumstances.

Based on our experience, we envisage the following steps to ensure that RRI principles can be integrated into transitional economies or less developed regions.

\subsection{Raising Awareness}

The starting point should be an effective dissemination of the concept. A couple of committed actors are needed who will start the task. They should seize all opportunities for promoting the concept itself and the societal message behind it in public communication. Good opportunities may be provided by communication panels of those investments with broader social consensus or the dissemination of results achieved in equal opportunity programs. The scientific community would also be fertile ground for seeding responsibility, as would organizing thematic conferences and workshops to spread the concept of RRI.

Taking advantage of grant-driven innovation, in the SEE countries RRI-orientated indicators should be introduced into the evaluation criteria for funding. This could be an effective direct incentive to promote RRI, not only for the final beneficiaries but also for intermediaries setting up proposals and managing the funding process. After having a pilot tender cycle, public authorities and business support organizations should consider making this RRI-driven evaluation criteria general and providing specific funding tools which support the measurable change of innovation activities towards responsibility.

As a later step, dedicated organizations for dissemination of the RRI concept and/or managing RI behavior should be established. These organizations may be created either by governmental bodies or by local authorities that wish to participate in RRI or by an NGO established by committed persons. The establishment by the Dutch government of KIR nano, ${ }^{8}$ with the aim of observing and monitoring the potential risks of nanotechnology, would be a good example for governmental initiatives. The recently established First Hungarian Innovation Association ${ }^{9}$ aiming to spread the RRI idea is an exemplary NGO for the SEE countries.

\subsection{Increasing Passive Knowledge}

Beyond explicit awareness-raising, it is important to have less obvious initiatives embedding RRI into the passive knowledge of society.

The branding initiative of the Development Centre for the Heart of Slovenia is a good example of a hidden action, which can raise awareness by using branding as a well-known indirect method. The applied brand 'Heart of Slovenia' 10 ensures that the manufacturing process of these branded local products (handicrafts, culinary products, dishes and tourism products) takes into account some social, environmental and ethical aspects. It helps to create a group of conscious customers who appreciate high-quality, locally-produced and socially responsible products. This branding also helps to preserve jobs in rural areas. Slovenian branding is not the sole initiative in this region; a similar regional branding is applied in Montenegro with the title 'The best our Mountains have to offer'. ${ }^{11}$ 
Another way to improve responsibility is to make people conscious of gender issues. Supporting sustainable business models for female entrepreneurs in traditional economic activities promotes cultural heritage and - similar to branding, mentioned previously - helps preserve countryside jobs and therefore prevents depopulation. The women's cooperatives of the North Aegean region and especially the cooperatives of Lesvos Island are examples of using traditional innovations of local product development as a determinative know-how in sustainable women's business. The small guide addressed to existing or potential local female entrepreneurs helps them to create, sustain and run their small-scale business by using their traditions. Their traditional environment-friendly and bio-food products also provide the opportunity to embed such businesses in the local community.

\subsection{Bottom-up Approach}

A bottom-up approach in this context means embedding RRI principles in local and regional politics. A good example is the Hungarian approach whereby the regional decision-makers were convinced about the importance of RRI principles thanks to a bottom-up, informal process facilitated through experts from the academic sector.

The main priority is to engage all the relevant actors and stakeholders of the region with the concept of RRI. The methodology covers three means of involvement: target group dissemination, wider dissemination and dissemination proposed to policy makers. Target group dissemination should focus on different stakeholder groups, reaching them through individual messages and channels. For wider dissemination, the engaged stakeholder groups can use their networks to promote the concept, collect new input and make recommendations on the use of RI in the region. To achieve consideration of RRI principles in policy - either as a funding basis or horizontal goal in developmental or institutional strategies - personal and informal cooperation with policy makers and funding organizations is also needed.

In connection with implementing the RRI-approach into policies, a pilot action was carried out within the FaRInn project. In Hungary the planning of the Economic and Innovation Operational Program has been led by government ministries. As RRI has a strong connection to this operational program, the University of Szeged, as a key innovation actor and stakeholder, officially requested that the ministry include the implementation of RRI in the new operational program. Despite intense personal contact and meetings, the bureaucratic process at national level meant that the suggestion did not reach the final decision-making table. Therefore, the former top-down and formal strategy was changed to a bottom-up informal approach: the decision-makers of the regional operative program were regularly invited to the FaRInn project's Local Steering Committee meetings and they became familiar with the concept of RRI. The same was then suggested to them as representatives of the national operational program and they made the decision to involve the RRI concept in the regional operational program.

\subsection{Successful Regional and Local Pilots}

Regional and local pilot projects can become success stories illustrating the implementation of RRI. Successfully implemented pilot projects with RRI focus can set positive 
benchmark examples for other actors in the given territorial unit. The FaRInn project set up several excellent pilot projects which might be good starting points for other regions. One of these pilots implementing the RRI approach in policies has been presented in section 5.3. The following pilots also should be highlighted:

- Stakeholder engagement events. At the beginning of the FaRInn project the announcement of an event with a clear RRI-topic in its title was unsuccessful; a very small number of people registered for the conference. The best way to proceed was to link the event to a different title and content of importance to the potential RRI target group. This topic was the planning of the 2014-20 programming period, and in the middle of the program a short presentation about RRI was given. The ratio of RRI-specific presentations in these events was gradually increased; thus this passive knowledge about RRI became increasingly active and participants became more interested in the RRI topic. The final event was announced with the topic and title of RRI and a large number of participants registered. Towards the end of the program, 15 researchers, who had not previously heard about RRI, became familiar with the RRI approach and involved the topic in their research. ${ }^{12}$

- Integrating living laboratories - as an RRI element - in local innovation ecosystems, as in the case of Forli-Cesena, may provide elements of inspirational RRI story-telling. In a contractual network of enterprises of different sizes and from different sectors with high potential, young graduates got together in an open-innovation environment to, first, brainstorm on innovative ideas and then cooperate by shaping these into products and services. The process included input and technical support from experts in various fields, for example, design, aesthetics, market trends, technology foresight, green economy, energy management, new materials and crowd-funding. Designed innovations must be socially and environmentally accountable. After a series of meetings with external experts from various disciplines, the enterprises involved proceeded to brainstorm to generate innovative ideas. All ideas went under a double-check by means of group and plenary discussion. Ideas that showed some potential were allocated to groups of members for further development.

- The integration of stakeholders' views through the living laboratory represents a practical, although far from simple, solution for adopting a responsible approach to innovation. Responsible research and innovation is largely debated at theoretical level, however enterprises need tools to implement the concept within their strategies and operations. Living laboratories are a tangible methodology for stakeholder engagement, which is a necessary element of RI.

\section{CONCLUDING REMARKS}

Introducing RRI tools into lagging regions may play a major role in shaping local economic models, largely requiring massive revisions to become more competitive. However, as shown in this chapter, the introduction is strongly influenced by the special characteristics of these countries. Although RRI theory and a majority of its implementation tools have already been developed, tailored and tested in more advanced countries, 
the above statements should carefully be taken into consideration when promoting RRI in less advanced regions.

The FaRInn project produced an initial base of knowledge and understanding on RRI in less advanced regions. This was a pioneering cooperation project with important accomplishments, which helped stakeholders to step forward. However, comprehensive strategic intervention needs further research and a more structured process of introducing existing RRI instruments that have been developed by academia and tested in other geographical areas. This would help innovation actors to develop an RRI toolbox that can stand them in good stead in the long-term, strategic integration of this concept into their innovation systems in South-East Europe.

\section{NOTES}

1. The FaRInn project was co-financed by the South-East Europe (SEE) transnational cooperation program whose aims are to improve integration and competitiveness in 16 countries and some regions of Italy and Ukraine.

2. http://ec.europa.eu/regional_policy/sources/docgener/informat/2014/fiche_innovation_en.pdf (accessed 3 May 2015).

3. The Bologna Process is a series of ministerial meetings and agreements, between European countries, designed to ensure comparability in the standards and quality of higher education qualifications. The process has created the European Higher Education Area. It is named after the place it was proposed, the University of Bologna, with the signing of the Bologna declaration by ecucation ministers from 29 European countries in 1999, forming a part of European integration.

4. Lukovics, M., N. Buzás, J. Huntingford and G. Bubbolini, 'Facilitating responsible innovation in the South-East European countries', Journal of Responsible Innovation (submitted).

5. The annual Innovation Union Scoreboard provides a comparative assessment of the research and innovation performance of EU member states and the relative strengths and weaknesses of their research and innovation systems.

6. The responsible research and innovation (RRD) Science and Technology Survey was carried out by TNS Opinion \& Social network in the 27 EU member states and Croatia between the 26 April and 14 May 2013.

7. The geographical distribution of the respondents is broad: Albania, Australia, Austria, Belgium, Bulgaria, Cyprus, the Czech Republic, Denmark, Finland, France, Germany, Greece, Ireland, Israel, Italy, Japan, Lithuania, Luxembourg, the Netherlands, Norway, Poland, Portugal, Spain, Sweden, Switzerland, Turkey and the UK.

8. http://www.rivm.nl/Onderwerpen/N/Nanotechnologie/Kennis_en_informatiepunt_risico_s_KIR_Nanote chnologie (accessed 13 May 2015).

9. http://www.rri.hu (accessed 20 May 2015).

10. http://www.euromontana.org/en/brand-of-territorial-marketing-the-heart-of-slovenia/ (accessed 20 May 2015).

11. http://www.bjelasica-komovi.me/wp-content/uploads/Brosure/Najbolje $\% 20$ sa $\% 20$ nasih $\% 20$ planina $\% 20$ eng .pdf (accessed 30 May 2015).

12. At the end of the project, a book was published containing these works. The book can be downloaded at $\mathrm{http}: / / \mathrm{www}$.eco.u-szeged.hu/english/research/scientific-publications/responsible-innovation (accessed 31 May 2015).

\section{REFERENCES}

European Commission (EC) (2012), 'Regional innovation in the Innovation Union', Project financed by the 6th Framework Programme for Research, for the implementation of the specific programme 'Strengthening the foundations of the European Research Area' (DG RTD 2005 M 02 02), prepared by H. Kroll, T. Stahlecker, V. Peter and L. Rivera Leon of Fraunhofer ISI, Technopolis Belgium, Directorate-General for Research and Innovation Capacities: Support for the Coherent Development of Research Policies, EUR 25191 EN. 
European Commission (EC) (2013a), South East Europe (SEE) Operational Program, Brussels: European Commission.

European Commission (EC) (2013b), 'Options for strengthening responsible research and innovation: report of the expert group on the state of art in Europe on responsible research and innovation', Directorate-General for Research and Innovation, Science in Society, EUR25766 EN, European Commission, Brussels.

European Commission (EC) (2014a), 'Innovation Union 2013 competitiveness report', Commission Staff Working Document, Directorate-General for Research and Innovation, EUR 25650 EN, European Commission, Brussels.

European Commission (EC) (2014b), 'Innovation union scoreboard 2014', Directorate-General for Research and Innovation, European Commission, Brussels.

Eurostat (2015), 'National statistics', Eurostat, Brussels.

Fisher, E. and G. Maricle (2014), 'Higher-level responsiveness? Socio-technical integration within US and UK nanotechnology research priority setting', Science and Public Policy, 42 (1), 72-85.

Guston, D.H. (2008), 'Innovation policy: not just a jumbo shrimp', Nature, 454 (7207), 940-41.

Owen R., P. Macnaghten and J. Stilgoe (2012), 'Responsible research and innovation: from science in society to science for society, with society', Science and Public Policy, 39 (6), 75I-60.

Owen, R., J. Stilgoe, P. Macnaghten, M. Gorman, E. Fisher and D. Guston (2013), 'A framework for responsible innovation', in R. Owen, J. Bessant and M. Heintz (eds), Responsible Innovation: Managing the Responsible Emergence of Science and Innovation in Society, London: Wiley, pp. 27-50.

Schumpeter, J.A. (1912), The Theory of Economic Development, repr. 2004, New Brunswick, NJ: Transaction.

Stankovic, M., B. Angelova, V. Janeska and B. Stankovic (2013), 'Science and innovation policy in Southeast Europe: brain drain as brain gain', International Journal of Technological Learning, Innovation and Development, 6 (3), 262-82.

United Nations Educational, Scientific, and Cultural Organization (UNESCO) (2009), 'Science, higher education and innovation policy in South Eastern Europe', UNESCO Regional Bureau for Science and Culture in Europe, Venice.

Von Schomberg, R. (2013), 'A vision for responsible research and innovation', in R. Owen, J. Bessant and M. Heintz (eds), Responsible Innovation: Managing the Responsible Emergence of Science and Innovation in Society, Chichester: John Wiley, pp. 51-74. 